\title{
EXAMINING CRASH VARIABLE BASED ON COLLISION TYPE FOR PREDICTING CRASH SEVERITY ON URBAN HIGHWAYS
}

\author{
Govindaraju Vijay ${ }^{1}$, Ramesh Adepu ${ }^{2}$, Kumar Molugaram ${ }^{3}$ \\ 1,2 Department of Civil Engineering, VNR Vignana Jyothi Institute of Engineering and Technology, \\ Hyderabad, Telangana, India \\ ${ }^{3}$ Department of Civil Engineering, University College of Engineering Osmania University, Hyderabad, \\ Telangana, India
}

Received 1 April 2016; accepted 11 July 2017

\begin{abstract}
Transportation facilities are the backbone for any economic growth in country's development. However, presently highways are the biggest threat to the world as they account for the largest number of road crashes. As a highway engineer emphasis should be made on reducing the occurrence of road crashes and understanding the causative factors. It is also important to understand the relationships between the severities of a road crash in the context with collision types. Several studies were carried on factors that influence on severity of crashes. The present paper attempts to explore the various factors associated with crash prediction on Indian highway. The study was conducted on National Highway NH-44 in Hyderabad city of Telangana State. Multinomial logit model was used for assessing the variables that influence the crash severity. The model reveals that vehicle type plays a major role in increasing the severity of the crash on highways. The model will be useful for the highway planner while improving the road section reducing the number of crashes.
\end{abstract}

Keywords: crash, collision, highway, multinomial logit.

\section{Introduction and Review of Literature}

An in-depth understanding of the random nature of crash process is one of the most interesting as well as essential aspects of traffic safety analysis. These will be widely used in practical implications for providing a safe transportation facility. In India, the highest number of fatal road crashes occurs on National Highways ( $\mathrm{NH}$ ) as $32.6 \%$ followed by State Highways ( $\mathrm{SH}$ ) as $27.8 \%$ fatality (NCRB, 2014). Understanding 'the random nature of crash process' on highway segments is of utmost importance as this can pave way for timely interventions to save precious lives. In this context a study was conducted on NH 44 from Suchitra to Tupran for about $40 \mathrm{kms}$ in length in Hyderabad city of Telangana State. It is observed that 802 crashes have occurred during the last 5 years period on this highway segment. This paper explains the causative factors that influence the collision pattern for occurrence of crash. Several studies were carried during a decade period for developing crash prediction models through statistical tools.

Shankar et al., (1995) used a negative binomial model to estimate crash frequencies and concluded that separate regression models shall be used for different types of crashes which will explain much better than

\footnotetext{
${ }^{2}$ Corresponding author: ramesh_a@vnrvjiet.in
} 
a single crash model. Khattak et al., (1998) estimated binary probit models to analyse severity of crashes during adverse weather conditions and identified that the frequency of crashes is higher during adverse weather but their severity is low. Dissanayake and $\mathrm{Lu}$ (2002) explained that a set of binary logistic regression models for single-vehicle crash data and identified important factors that result in higher crashes and severe injuries. Abdel-Aty (2003) analysed the severity of crashes at different locations using ordered probit models and identified variables that significantly cause severe injuries for that particular location. Donnell and Mason (2004) developed logistic regression models for cross-median and median crashes by considering the severity of a crash as ordinal response and nominal response respectively. Lord et al., (2005) utilized zero-inflated Poisson and negative models on crash data and concluded that these are the most reliable models when crash count data has a large number of samples that are 'perfectly safe'. Lord (2006) fitted Poisson-gamma models on crash data that has a low sample mean and small sample size and showed that they have a very serious effect on the estimated parameters of the model and reduce the reliability of the model. Qin et al., (2006) investigated the relationship between crash occurrence and hourly volume by fitting binary regression models. He has concluded that the relationship between crash types and independents is non-linear in nature. Kim et al., (2007) applied multilevel binomial logistic models in order to predict the probability of different crashes based on the hypothesis that the intersection crashes are hierarchical in nature. Huang et al., (2008) established a Bayesian hierarchical binomial logistic model and identified that light weight vehicles cause major injuries. Quddus et al., (2009) used ordered-response models to observe the effect of traffic congestion on crash severity and found that there is no relationship between them. Geedipally et al., (2010) developed multinomial logit models for different crash types and found that predicting crash counts by specific crash type is the best among the existing methods. Ramesh and Kumar (2011) explained the current road safety level in Hyderabad city. Multinomial regression analysis was carried for analysing accident prediction model. Black spots were also identified using statistical methods. Yasmin and Eluru (2013) compared various crash data models and concluded that mixed generalized ordered logit competes with mixed multinomial logit in modelling crash type data. Ye and Lord (2014) examined the effect of sample size and concluded that ordered probit model can work efficiently for smaller sample sizes. De Luca (2015) worked on accident data using multivariate analysis and artificial neural networks and concluded that multivariate analysis is more efficient in the analysis of blackspots. Niveditha et al., (2015) explained that logit models are suitable for prediction of the crash. The results explain that shoulder condition is an affecting factor for the occurrence of non-fatal crashes in the city.

Most of the literature was on homogenous traffic condition. A few studies in India, particularly for our city were conducted in analysing the causative factors of crash on highways. In the present work, multinomial logit model is used for understanding different crash types. Five characteristics were considered namely, causes of crashes, road curve radius, the type of vehicle that caused the crash, the pavement condition during which the crash has occurred and time of crash. It is hypothesized that these characteristics influence the severity of the crash.

\section{ijtte 382}




\section{Methodology}

Multinomial Logit (MNL) Model was used in predicting the impact of crashes on the basis of collision type. This is accomplished by establishing a relationship between the severity of the crash and crash variables. Table 1 provides the crash variables and its code used for model development.
Hosmer and Lemeshow (2000) mathematical expressions were used for model development, where $\mathrm{Y}$ is considered as severity of the crash and $x_{1}, x_{2}, x_{3}, x_{4}, x_{5}$ as crash variables. $Y$ consists of 4 levels namely non injury, minor injury, grievous injury and fatal injury. We have three logit functions as $\log i t_{1}, \log i t_{2}, \log i t_{3}$, expressed mathematically as below.

$$
\begin{aligned}
& \text { logit }_{1}=\ln \left[\frac{P(Y=1 \mid x)}{P(Y=0 \mid x)}\right]=\beta_{10}+\beta_{11} x_{1}+\beta_{12} x_{2}+\beta_{13} x_{3}+\beta_{14} x_{4}+\beta_{15} x_{5} \\
& \text { logit }_{2}=\ln \left[\frac{P(Y=2 \mid x)}{P(Y=0 \mid x)}\right]=\beta_{20}+\beta_{21} x_{1}+\beta_{22} x_{2}+\beta_{23} x_{3}+\beta_{24} x_{4}+\beta_{25} x_{5} \\
& \text { logit }_{3}=\ln \left[\frac{P(Y=3 \mid x)}{P(Y=0 \mid x)}\right]=\beta_{30}+\beta_{31} x_{1}+\beta_{32} x_{2}+\beta_{33} x_{3}+\beta_{34} x_{4}+\beta_{35} x_{5}
\end{aligned}
$$

Where: $\log i t_{1}$ represents a logit function for Minor Injury versus Non-Injury, logit for Grievous Injury versus Non-Injury and $\log _{3}$ for Fatal Injury versus Non-Injury. $\beta_{10}, \beta_{20}, \beta_{30}$ represent the intercepts and the remaining $\beta$ 's represent the coefficients of the characteristics.

The odds ratio is the exponent of the coefficient obtained for characteristic in the logit model. When odds ratio $<1$, there is a higher chance for occurrence of noninjury. If the odds ratio $>1$, it implies that an increase in the level of crash variable/ characteristic leads to a higher chance of occurrence of crash severity, i.e. minor injury for $\operatorname{logit}_{1}$, grievous injury for $\log _{2} t_{2}$ and fatal injury for $\operatorname{logit}_{3}$. MNL model is tested for its significance using likelihood ratio. The statistical analysis was implemented by multinom() in nnet package of R 3.3.1.

\section{Data Collection}

Crash data was collected on National Highway 44 (NH-44) for 5yrs period (201116) along the study stretch. The length of study stretch is $40 \mathrm{~km}$ from Suchitra X-road to Tupran of Telangana State and is shown in Fig 1. 


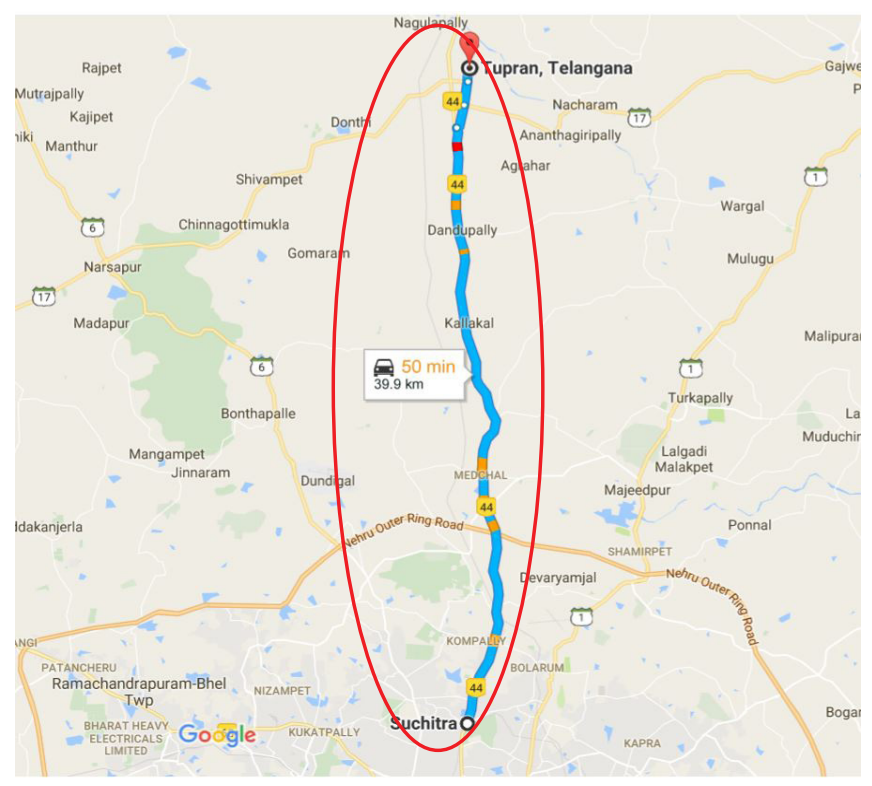

Fig. 1.

Study Location for Crash Analysis

It is observed from the data that crash is influencing the following collision types:
a) Head-on Collision
b) Rear-end Collision
c) Side swipe Collision.

The true impact of collision type shall be used in assessing the severity of the crash. The severity of crash in the study location is observed in four levels ("Severity of Crash/ Code”): Non-Injury/0, Minor Injury/1, Grievous Injury/2, Fatal Injury/3.

\section{Table 1}

Variables Influencing Severity of Crash

\begin{tabular}{|c|c|c|}
\hline S.No. & Crash characteristic & Codes \\
\hline 1 & Causes & $\begin{array}{c}1=\text { Drunken Driving } \\
2=\text { Drowsing } \\
3=\text { Over speeding } \\
4=\text { Vehicle out of control } \\
5=\text { Fault of two-wheeler } / \text { pedestrian } \\
6=\text { Defect in condition of vehicle condition }\end{array}$ \\
\hline 2 & Road curve radius & $\begin{array}{c}1=\text { Straight Road } \\
2=\text { Slight Curve }-750 \leq \mathrm{R} \leq 900 \mathrm{~m} \\
3=\text { Sharp Curve }-300 \leq \mathrm{R} \leq 400 \mathrm{~m}\end{array}$ \\
\hline 3 & Vehicle responsible & $\begin{array}{c}1=\text { Light weight } \\
2=\text { Heavy weight }\end{array}$ \\
\hline 4 & Pavement Condition & $\begin{aligned} & 1=\text { Dry Pavement } \\
& 2=\text { Wet Pavement (Rain) }\end{aligned}$ \\
\hline 5 & Day/Night & $\begin{array}{c}1=\text { Day } \\
2=\text { Night }\end{array}$ \\
\hline
\end{tabular}


Crash characteristics and severity of crash for each collision type is shown in Table 2 .

Table 2

Summary of Crash Characteristics

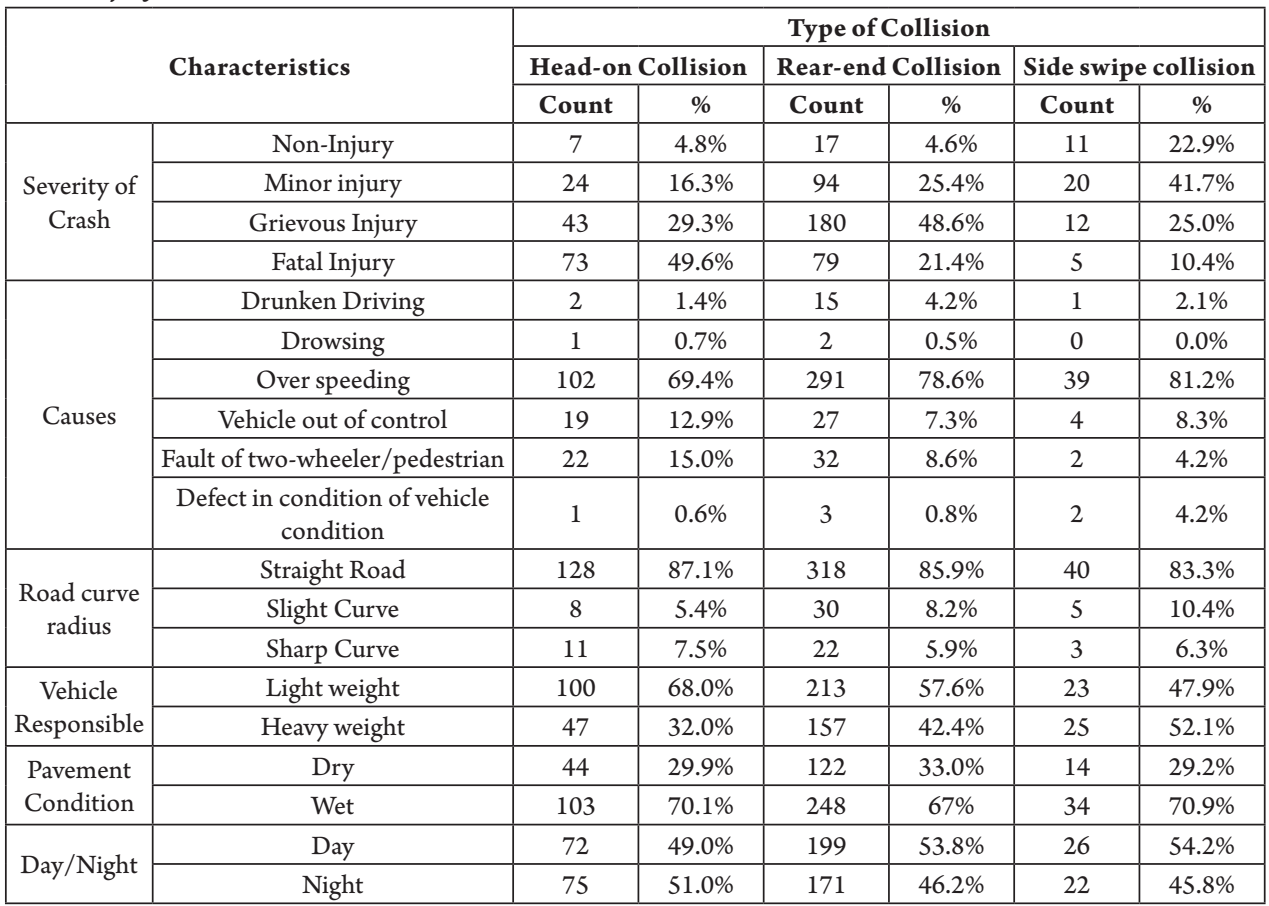

\section{Model Interpretation and Findings}

Four Multinomial logistic models are developed to predict the severity of the crash. The first MNL explains on total Collisions and the remaining three models explain on Head-on Collision, Rear-end Collision and Sideswipe Collision respectively. The coefficients of characteristics along with their Standard Errors (SE) and odds ratios are computed for each model. A Z-statistic with its $\mathrm{p}$-value is observed for estimated coefficients which explain the influence of crash variables in the model. These are presented in the tables 3-7.
Table 3 interprets that for logit, the coefficients of causes, road curve radius and pavement condition are positive, implying that a unit increase in these characteristics is associated with an increase in the chance of injury being a minor injury. The coefficients of the vehicle responsible and day/night are negative, indicating that a unit decrease in these characteristics results in an increase in the chance of minor injury. The odds ratio is greater than 1 for causes, road curve radius and pavement condition; further if the values of these characteristics increase, there is a higher chance of minor injury. The odds ratio is less than 1 for vehicle responsible 
and day/night indicating a higher chance for non-injury when the values of these characteristics increase.

In case of $\operatorname{logit}_{2}$ two characteristics namely causes and pavement condition have positive coefficients implying that a unit increase in these characteristics results in an increase in the chance of grievous injury. A unit decrease in road curve radius, vehicle responsible and day/night leads to an increase in the chance of grievous injury. The odds ratios of causes and pavement condition are greater than 1 implying that a grievous injury has a higher chance of occurrence as the values of these characteristics increase. The odds ratios for road curve radius, vehicle responsible and day/night are less than 1 indicating that the chance of occurrence of non-injury increases as the values of these characteristics increases.
In $\operatorname{logit}_{3}$, all characteristics except vehicle responsible have positive coefficients indicating that a unit increase in each of these characteristics implies a corresponding increase in the chance of fatal injury. The characteristic vehicle responsible has a negative coefficient implying that a unit increase in this characteristic decreases the chance of fatal injury. The odds ratio of causes, road curve radius, pavement condition and day/night is greater than 1 depicting that an increase in the values of these characteristics results in a higher chance for occurrence of fatal injury. The odds ratio of vehicle responsible is less than 1 which means that increase in the value of this characteristic leads to a higher chance of non-injury. Tables 4, 5 and 6 interpret for head-on, rear-end and side swipe collision types with the characteristics influencing severity of crash.

\section{Table 3}

Estimated Coefficients, Standard Errors and Their Odds Ratios for Total Collisions MNL Model

\begin{tabular}{|c|c|c|c|c|c|c|}
\hline & Characteristics & Coefficients & SE & $\mathbf{Z}$ & p-value & odds ratio \\
\hline \multirow{6}{*}{$\operatorname{logit}_{1}$} & (Intercept) & 5.2000 & 1.6541 & 3.1437 & 0.0017 & \\
\hline & Causes & 0.4178 & 0.2658 & 1.5719 & 0.1160 & 1.5186 \\
\hline & Road curve radius & 0.1922 & 0.2913 & 0.6596 & 0.5095 & 1.2119 \\
\hline & Vehicle Responsible & -2.6710 & 0.6297 & -4.2416 & $0.0000^{*}$ & 0.0692 \\
\hline & Pavement condition & 0.0719 & 0.2164 & 0.3325 & 0.7395 & 1.0746 \\
\hline & Day/Night & -0.5704 & 0.3958 & -1.4411 & 0.1496 & 0.5653 \\
\hline \multirow{6}{*}{$\operatorname{logit}_{2}$} & (Intercept) & 6.8400 & 1.6261 & 4.2065 & 0.0000 & \\
\hline & Causes & 0.3771 & 0.2602 & 1.4489 & 0.1474 & 1.4580 \\
\hline & Road curve radius & -0.0042 & 0.2919 & -0.0143 & 0.9886 & 0.9958 \\
\hline & Vehicle Responsible & -3.1532 & 0.6217 & -5.0721 & $0.0000^{*}$ & 0.0427 \\
\hline & Pavement condition & 0.1228 & 0.2101 & 0.5846 & 0.5588 & 1.1307 \\
\hline & Day/Night & -0.6590 & 0.3851 & -1.7114 & 0.0870 & 0.5174 \\
\hline \multirow{6}{*}{$\operatorname{logit}_{3}$} & (Intercept) & 4.9150 & 1.6462 & 2.9857 & 0.0028 & \\
\hline & Causes & 0.4085 & 0.2636 & 1.5499 & 0.1212 & 1.5046 \\
\hline & Road curve radius & 0.0402 & 0.2954 & 0.1359 & 0.8919 & 1.0410 \\
\hline & Vehicle Responsible & -2.8690 & 0.6268 & -4.5772 & $0.0000^{*}$ & 0.0568 \\
\hline & Pavement condition & 0.0927 & 0.2137 & 0.4337 & 0.6645 & 1.0971 \\
\hline & Day/Night & 0.0270 & 0.3933 & 0.0687 & 0.9452 & 1.0274 \\
\hline
\end{tabular}

'*' indicates a significant characteristic 
Table 4

Estimated Coefficients, Standard Errors and Their Odds Ratios for Head-on Collision MNL Model

\begin{tabular}{|l|l|c|l|l|l|l|}
\hline & \multicolumn{1}{|c|}{ Characteristics } & Coefficients & \multicolumn{1}{|c|}{ SE } & \multicolumn{1}{|c|}{$\mathbf{Z}$} & p-value & odds ratio \\
\hline $\operatorname{logit}_{1}$ & Intercept) & 22.9207 & 1.4946 & 15.3357 & 0.0000 & \\
\hline & Causes & 1.1562 & 1.1556 & 1.0005 & 0.3170 & 3.1778 \\
\hline & Road curve radius & 0.0376 & 0.5668 & 0.0663 & 0.9472 & 1.0383 \\
\hline & Vehicle Responsible & -12.5530 & 1.8545 & -6.7691 & $0.0000^{*}$ & 0.0000 \\
\hline & Pavement condition & 0.0913 & 0.5560 & 0.1643 & 0.8695 & 1.0957 \\
\hline $\operatorname{logit}_{2}$ & Day Night & -1.2169 & 1.0094 & -1.2055 & 0.2280 & 0.2962 \\
\hline & Intercept) & 22.8150 & 1.3140 & 17.3634 & 0.0000 & \\
\hline & Causes & 1.2176 & 1.1400 & 1.0681 & 0.2855 & 3.3791 \\
\hline & Road curve radius & -0.0968 & 0.5549 & -0.1745 & 0.8615 & 0.9077 \\
\hline & Vehicle Responsible & -12.4542 & 1.8444 & -6.7523 & $0.0000^{*}$ & 0.0000 \\
\hline & Pavement condition & -0.0495 & 0.5266 & -0.0940 & 0.9251 & 0.9517 \\
\hline & Day Night & -0.6088 & 0.9497 & -0.6410 & 0.5215 & 0.5440 \\
\hline & (Intercept) & 21.7772 & 1.2442 & 17.5024 & 0.0000 & \\
\hline & Causes & 1.2411 & 1.1337 & 1.0947 & 0.2736 & 3.4595 \\
\hline & Road curve radius & 0.0548 & 0.5342 & 0.1026 & 0.9183 & 1.0564 \\
\hline & Vehicle Responsible & -12.5286 & 1.8492 & -6.7752 & $0.0000^{*}$ & 0.0000 \\
\hline & Pavement condition & 0.0588 & 0.5150 & 0.1141 & 0.9092 & 1.0605 \\
\hline & Day Night & 0.1499 & 0.9308 & 0.1611 & 0.8720 & 1.1618 \\
\hline
\end{tabular}

'*' indicates a significant characteristic

\section{Table 5}

Estimated Coefficients, Standard Errors and Their Odds Ratios for Rear-end Collision MNL Model

\begin{tabular}{|l|l|c|c|c|c|c|}
\hline & Characteristics & Coefficients & SE & $\mathbf{Z}$ & p-value & odds ratio \\
\hline $\operatorname{logit}_{1}$ & (Intercept) & 5.7870 & 2.1843 & 2.6494 & 0.0081 & \\
\hline & Causes & 0.3896 & 0.3563 & 1.0934 & 0.2742 & 1.4763 \\
\hline & Road curve radius & 0.0437 & 0.3782 & 0.1155 & 0.9080 & 1.0447 \\
\hline & Vehicle Responsible & -1.8816 & 0.7986 & -2.3561 & $0.0185^{*}$ & 0.1523 \\
\hline & Pavement condition & -0.1400 & 0.2970 & -0.4714 & 0.6374 & 0.8694 \\
\hline $\operatorname{logit}_{2}$ & Day/Night & -1.1606 & 0.6209 & -1.8692 & 0.0616 & 0.3133 \\
\hline & Intercept) & 7.8845 & 2.1546 & 3.6593 & 0.0003 & \\
\hline & Causes & 0.2510 & 0.3513 & 0.7143 & 0.4751 & 1.2853 \\
\hline & Road curve radius & -0.2312 & 0.3819 & -0.6055 & 0.5448 & 0.7936 \\
\hline & Vehicle Responsible & -2.6680 & 0.7859 & -3.3947 & $0.0007^{*}$ & 0.0694 \\
\hline & Pavement condition & 0.0781 & 0.2906 & 0.2689 & 0.7880 & 1.0813 \\
\hline & Day/Night & -1.1640 & 0.6099 & -1.9085 & 0.0563 & 0.3122 \\
\hline & (Intercept) & 5.6525 & 2.2041 & 2.5645 & 0.0103 & \\
\hline & Causes & 0.0244 & 0.3633 & 0.0671 & 0.9465 & 1.0247 \\
\hline & Road curve radius & -0.1232 & 0.3925 & -0.3138 & 0.7537 & 0.8841 \\
\hline & Vehicle Responsible & -1.8864 & 0.8007 & -2.3558 & $0.0185^{*}$ & 0.1516 \\
\hline & Pavement condition & 0.0820 & 0.2991 & 0.2740 & 0.7841 & 1.0854 \\
\hline & Day/Night & -0.5758 & 0.6285 & -0.9160 & 0.3596 & 0.5623 \\
\hline
\end{tabular}

\footnotetext{
'*' indicates a significant characteristic
} 
Table 6

Estimated Coefficients, Standard Errors and Their Odds Ratios for Side Swipe Collision MNL Model

\begin{tabular}{|c|c|c|c|c|c|c|}
\hline & Characteristics & Coefficients & SE & $\mathbf{Z}$ & p-value & odds ratio \\
\hline \multirow[t]{6}{*}{$\operatorname{logit}_{1}$} & (Intercept) & -9.3548 & 86.5357 & -0.1081 & 0.9139 & \\
\hline & Causes & 0.9952 & 0.9842 & 1.0112 & 0.3119 & 2.7053 \\
\hline & Road curve radius & 10.1107 & 86.4541 & 0.1169 & 0.9069 & 24604.5200 \\
\hline & Vehicle Responsible & -3.4603 & 1.2762 & -2.7113 & $0.0067^{*}$ & 0.0314 \\
\hline & Pavement condition & 0.9638 & 0.7245 & 1.3302 & 0.1834 & 2.6217 \\
\hline & Day/Night & 0.1816 & 0.9764 & 0.1860 & 0.8524 & 1.1992 \\
\hline \multirow[t]{6}{*}{$\operatorname{logit}_{2}$} & (Intercept) & -7.5927 & 86.5382 & -0.0877 & 0.9301 & \\
\hline & Causes & 0.5874 & 1.0149 & 0.5788 & 0.5627 & 1.7994 \\
\hline & Road curve radius & 10.0011 & 86.4540 & 0.1157 & 0.9079 & 22050.3200 \\
\hline & Vehicle Responsible & -2.6741 & 1.2801 & -2.0890 & $0.0367^{*}$ & 0.0690 \\
\hline & Pavement condition & 0.3340 & 0.7119 & 0.4692 & 0.6390 & 1.3965 \\
\hline & Day/Night & -0.2347 & 0.9754 & -0.2406 & 0.8098 & 0.7908 \\
\hline \multirow[t]{6}{*}{$\operatorname{logit}_{3}$} & (Intercept) & -11.3386 & 86.5894 & -0.1309 & 0.8958 & \\
\hline & Causes & 1.4736 & 1.1007 & 1.3388 & 0.1806 & 4.3650 \\
\hline & Road curve radius & 9.4845 & 86.4566 & 0.1097 & 0.9126 & 13153.6200 \\
\hline & Vehicle Responsible & -2.9676 & 1.5017 & -1.9761 & $0.0481^{*}$ & 0.0514 \\
\hline & Pavement condition & -0.2420 & 0.9219 & -0.2625 & 0.7930 & 0.7851 \\
\hline & Day/Night & 1.0776 & 1.3479 & 0.7995 & 0.4240 & 2.9375 \\
\hline
\end{tabular}

\footnotetext{
'*' indicates a significant characteristic
}

The results interpret that the above characteristics influence the severity of the crash. The crash variable vehicle responsible is observed as the major factor influencing crash severity. For all collision types, fourwheeler vehicles and below are considered as light weight vehicles and all vehicles above four-wheelers are considered as heavy weight vehicles in the analysis. It is observed from the results that light weight vehicles have a higher severity of crashes as opposed to heavy weight vehicles.

\section{Table 7}

Goodness-of-fit Statistics

\begin{tabular}{|c|c|c|c|}
\hline Collision type & log-likelihood & Chi-Square & p-value \\
\hline Total & -791.760 & 73.689 & $<0.0001$ \\
\hline Head-on & -168.760 & 28.706 & 0.017 \\
\hline Rear-end & -432.840 & 48.983 & $<0.0001$ \\
\hline Side swipe & -61.660 & 25.495 & 0.0437 \\
\hline
\end{tabular}


The log-likelihood measure values for total collisions, head-on, rear-end and Sideswipe are significant at $5 \%$ level of significance which concludes that these models provides a good fit to the data.

\section{Conclusions}

The paper introduces a model-based mechanism to establish relationships between the nature of collisions and various characteristics, namely; causes of crashes, road curve radius, vehicle type, pavement conditions and time of the crash. The severity of crashes is considered to be the systematic component of the nature of collisions in this study. Multinomial logit models are developed to understand the effect of these characteristics on the level of severity of the crash.

Statistical analysis and model interpretations conclude that the type of vehicle responsible for the crash plays an important role in determining the level of crash severity. This holds good for all the types of collisions considered in the study.

MNL model serves as an aid to the policymakers in framing norms to ensure that roads transform to safer spaces. Placement of warning signs, reflective mirrors and improved infrastructure design will improve safety for road users. The above model helps in predicting the level of severity of the crash based on the observed characteristics. This will pave way for timely interventions to save precious lives.

\section{References}

Abdel-Aty, M. 2003. Analysis of Driver Injury Severity Levels at Multiple Locations Using Ordered Probit Models, Journal of safety research 34(5): 597-603.
Dissanayake, S.; Lu, J. 2002. Analysis of Severity of Young Driver Crashes: Sequential Binary Logistic Regression Modelling, Transportation Research Record: Journal of the Transportation Research Board (1784): 108-114.

Donnell, E.; Mason Jr. J. 2004. Predicting the Severity of Median-Related Crashes in Pennsylvania by Using Logistic Regression, Transportation Research Record: Journal of the Transportation Research Board (1897): 55-63.

Geedipally, S.; Patil, S.; Lord, D., 2010. Examination of Methods to Estimate Crash Counts by Collision Type, Transportation Research Record: Journal of the Transportation Research Board (2165): 12-20.

Hosmer, D.W.; Lemeshow, S. 2000. Applied Logistic Regression (2nd ed.).Wiley. New York. USA. 369 p.

Huang, H.; Chin, H.C.; Haque, M.M. 2008. Severity of Driver Injury and Vehicle Damage in Traffic Crashes at Intersections: A Bayesian Hierarchical Analysis, Accident Analysis \& Prevention 40(1): 45-54.

Khattak, A.; Kantor, P.; Council, F. 1998. Role of Adverse Weather in Key Crash Types on Limited-Access: Roadways Implications for Advanced Weather Systems, Transportation Research Record: Journal of the Transportation Research Board (1621): 10-19.

Kim, D.G.; Lee, Y.; Washington, S.; Choi, K. 2007. Modeling Crash Outcome Probabilities at Rural Intersections: Application of Hierarchical Binomial Logistic Models, Accident Analysis \& Prevention 39(1): 125-134.

Lord, D. 2006. Modelling Motor Vehicle Crashes Using Poisson-Gamma Models: Examining the Effects of Low Sample Mean Values and Small Sample Size on the Estimation of the Fixed Dispersion Parameter, Accident Analysis \& Prevention 38(4): 751-766.

Lord, D.; Washington, S.P.; Ivan, J.N. 2005. Poisson, Poisson-Gamma and Zero-Inflated Regression Models of Motor Vehicle Crashes: Balancing Statistical Fit and Theory, Accident Analysis \& Prevention 37(1): 35-46. 
De Luca, M. 2015. A Comparision between Prediction Power of Artificial Neural Networks and Multivariate Analysis in Road Safety Management, Transport 1-7.

NCRB. 2014. National Crime Records Bureau 'Crash Statistics on Indian National and State Highways, New Delhi. Available from internet: <http://ncrb.nic.in/ index.htm>.

Niveditha, V.; Ramesh, A.; Kumar, M. 2015. Development of Models for Crash Prediction and Collision Estimation. A Case Study for Hyderabad city, International Journal of Transportation Engineering 3(2): 143-150.

Qin, X.; Ivan, J.N.; Ravishanker, N.; Liu, J.; Tepas, D. 2006. Bayesian Estimation of Hourly Exposure Functions by Crash Type and Time of Day, Accident Analysis \& Prevention 38(6): 1071-1080.

Quddus, M.A.; Wang, C.; Ison, S.G. 2009. Road Traffic Congestion and Crash Severity: Economic Analysis Using Ordered Response Models, Journal of Transportation Engineering 136(5): 424-435.
Ramesh A.; Kumar M. 2011. Road Accident Models for Hyderabad Metropolitan City of India, Journal of Indian Highways 39(7): 17-30.

Shankar, V.; Mannering, F.; Barfield, W. 1995. Effect of Roadway Geometrics and Environmental Factors on Rural Freeway Crash Frequencies, Accident Analysis \& Prevention 27(3): 371-389.

Yasmin, S.; Eluru, N. 2013. Evaluating Alternate Discrete Outcome Frameworks for Modelling Crash Injury Severity, Accident Analysis \& Prevention 59: 506-521.

Ye, F.; Lord, D. 2014. Comparing Three Commonly Used Crash Severity Models on Sample Size Requirements: Multinomial Logit, Ordered Probit and Mixed Logit Models, Analytic Methods in Accident Research 1: 72-85. 